\title{
TOMOGRAFIA SÍSMICA DE TEMPO DE PERCURSO COM ONDAS P APLICADA AO ESTUDO DO MANTO SUPERIOR SOB O CRÁTON AMAZÔNICO \\ Erverlon Bruno da Paixão Chaves ${ }^{1}$, Paulo Araujo de Azevedo², UFOPA
}

Copyright 2021, SBGf - Sociedade Brasileira de Geofísica.

This paper was prepared for presentation during the $17^{\text {th }}$ International Congress of the Brazilian Geophysical Society held in Rio de Janeiro, Brazil, $16-19$ August 2021.

Contents of this paper were reviewed by the Technical Committee of the $17^{\text {th }}$ International Congress of the Brazilian Geophysical Society and do not necessarily represent any position of the SBGf, its officers or members. Electronic reproduction or storage of any part of this paper for commercial purposes without the written consent of the Brazilian Geophysical Society is prohibited.

\section{RESUMO}

Apresentamos os resultados de tomografia sísmica de tempo de percurso utilizando ondas $\mathrm{P}$ no cráton Amazônico. O objetivo foi realizar um estudo do manto superior a partir das variações de velocidades adquiridas pelo método de forma a identificar a quilha cratônica sob o Cráton Amozônico. Os dados foram registrados entre os anos de 2016 e 2018 por 24 estações distribuídas na área de estudo e pertencentes a RSBR. Para refinar as marcações foi utilizado o método de correlação cruzada MCPCC (Correlação Cruzada de Fase Multicanal), onde a fase do sinal é utilizada em vez de amplitude. Identificamos uma anomalia de baixa velocidade entre os escudos das Guianas e do Brasil central, no qual relacionamos ao Domo de Monte Alegre. Outras anomalias de baixas velocidades observadas ao longo do alinhamento da tendência principal do Lineamento Transbrasiliano, correlacionam-se com a região de colisão entre as paleoplacas Amazônica e São Franciscana. Pode-se também correlacionar as anomalias de alta e baixa velocidades condizentes com domínios geocronológicos. Anomalias de altas velocidades detectadas em nossos resultados se correlacionam muito bem com toda a área mapeada e acredita-se que pelos resultados do imageamento tomográfico desta pesquisa e pelas interpretações em trabalhos anteriores dos pesquisadores, estas anomalias se relacionam com a borda da placa subduzida de Nazca sob a America do Sul. Anomalias de altas velocidades coincidiram com a localização da região do cráton Amazônico, e sugerindo a presença de uma quilha neste cráton com maior intensidade observada na região oeste do seu limite. O cráton amazônico alcança aproximadamente 250 a $300 \mathrm{~km}$ e abaixo dessas profundidades aparece a estrutura que relacionamos a quilha cratônica que se estenderia até $\sim 500 \mathrm{~km}$ de profundidade.

Palavras-chave: Tomografia sísmica. Cráton amazônico. Quilha cratônica. 